\title{
PREVALENCE OF ANAEMIA IN WOMEN OF REPRODUCTIVE AGE GROUP ATTENDING A TERTIARY CARE HOSPITAL OF UTTAR PRADESH
}

\author{
Anita Jain'1, Akhila Ayyagari², Ritika Prakash³, Bharati ${ }^{4}$ \\ ${ }^{1}$ Assistant Professor, Department of Obstetrics and Gynaecology, Saraswati Medical College, Lucknow, Uttar Pradesh, India. \\ ${ }^{2}$ Assistant Professor, Department of Obstetrics and Gynaecology, Saraswati Medical College, Lucknow, Uttar Pradesh, India. \\ 3 Senior Resident, Department of Obstetrics and Gynaecology, Saraswati Medical College, Lucknow, Uttar Pradesh, India. \\ ${ }^{4}$ Statistician and Tutor, Department of Obstetrics and Gynaecology, Saraswati Medical College, Lucknow, Uttar Pradesh, India.
}

\section{ABSTRACT}

\section{BACKGROUND}

Anaemia is a global health problem affecting developing and developed countries with major consequences for human health, social and economic development. Anaemia is more prevalent in reproductive women, pregnant women and young children. However, it is ignored even though it has serious consequences on health and national development. The state of Uttar Pradesh has a high prevalence of anaemia. The present study attempts to understand the association of some selected lifestyle indicators with anaemia level in rural area of Uttar Pradesh. It has been thought that such an attempt will benefit the policy makers in understanding the current situation and subsequent need for further program and planning.

Aims and Objective-

1. To estimate the prevalence of anaemia in reproductive women attending Saraswati Medical College, Unnao (U. P.)

2. To evaluate the association of socioeconomic and demographic variables with anaemia.

\section{MATERIALS \& METHODS}

The cross-sectional study was done at OBGYN clinic of Saraswati Medical College, Unnao, to determine the status of anaemia in pregnant women and various socio-demographic and dietary factors associated with it. Haemoglobin level of 449 women selected by consecutive sampling was estimated by Cyanmethaemoglobin method.

Statistical Analysis- Template generated in MS Excel and analysis was done using SPSS 23 software.

\section{RESULTS}

Out of total 449 women, anaemia was found to be present in 438 (96.45\%) women. A statistically significant association of anaemia $(\mathrm{p}<.05)$ was found with dietary factors. But the association of anaemia with age, religion, family type, education, occupation and socioeconomic status was not found to be statistically significant.

\section{CONCLUSION}

Occurrence of anaemia was much higher in this area as compared to national average. It indicates that anaemia continues to be a major public health problem. Efforts should be geared towards the early detection and treatment of anaemia.

\section{KEY WORDS}

Prevalence, Anaemia, Reproductive Age Group Women, Rural Uttar Pradesh.

HOW TO CITE THIS ARTICLE: Jain A, Ayyagari A, Prakash R, et al. Prevalence of anaemia in women of reproductive age group attending a tertiary care hospital of Uttar Pradesh. J. Evolution Med. Dent. Sci. 2019;8(07):425-429, DOI: 10.14260/jemds/2019/94

\section{BACKGROUND}

Anaemia is a global health problem affecting developing and developed countries with major consequences for human health, social and economic development. WHO estimates over one third of the world's population suffers from anaemia. ${ }^{1}$ India continues to be one of the countries with the highest prevalence of anaemia. ${ }^{2}$ The National Family Health Survey- 4 estimates, reveal the prevalence of anaemia to be $54.3 \%$ in women of reproductive age group. Anaemia is more prevalent in reproductive women, pregnant women and young children.

'Financial or Other Competing Interest': None.

Submission 19-12-2018, Peer Review 02-02-2019,

Acceptance 09-02-2019, Published 18-02-2019.

Corresponding Author:

Dr. Akhila Ayyagari,

Assistant Professor,

Department of Obstetrics and Gynaecology,

Saraswati Medical College,

Lucknow, Uttar Pradesh, India.

E-mail: aki.ayyagari@gmail.com

DOI: $10.14260 /$ jemds/2019/94

\section{(c) $(1)(-)$}

It leads to reduced work efficiency in adults and has an impact on cognitive development in children and adolescents. Anaemia in adolescent women affects their reproductive physiology. Anaemia during pregnancy is also associated with low birth weight babies, premature births, increased perinatal and neonatal morbidity. However, it is ignored even though it has serious consequences on health and national development.

About 1.62 billion of the world's population is suffering from anaemia. ${ }^{3}$ The burden predominantly falls on Asia and Africa with complex interplay of socioeconomic status, dietary factors, infectious diseases, genetics and other factors determining anaemia.4 Anaemia among women is an important contributor to maternal mortality and morbidity, lowered physical activity and lowered productivity. ${ }^{5-6}$ In developing countries, women are more vulnerable, particularly with respect to their health, health care facilities and dietary habits. Anaemia has a potential influence on the overall women health and has been a concern for the government of India. The present study attempts to understand the association of some selected lifestyle indicators with anaemia level in rural area of Uttar Pradesh. It 
has been thought that such an attempt will benefit the policy makers in understanding the current situation and subsequent need for further program and planning.

\section{Aims and Objectives}

3. To estimate the prevalence of anaemia in reproductive women attending Saraswati Medical College, Unnao (U. P.)

4. To evaluate the association of socioeconomic and demographic variables with anaemia.

\section{MATERIALS AND METHODS}

The present cross-sectional study was carried out in a tertiary care centre in rural North India. All women attending the outpatient clinic of department of obstetrics and gynaecology were included in the study. Study was carried out from June 2018 to November 2018. A total of 451 females were included in the study. Convenience sampling method was used in the present study A structured pre-tested interview schedule was used and written informed consent was taken prior to data collection and blood sampling from patients. The schedule consisted of socioeconomic and demographic information of the women and they were divided into groups on the basis of age (15-25, 25-35, 35-45), religion (Hindu, Muslim), education level (Illiterate, primary- $<=5^{\text {th }}$ standard, secondary- $>5^{\text {th }}$ standard), occupation (Working and Housewife), family type (Nuclear and joint family) socioeconomic status according to modified B.G. Prasad classification (Lower, Lower middle, Middle). Lifestyle behaviour variables such as consumption of fruits green vegetables, non-vegetarian diet, pulses, milk and curd were considered. Out of 451 two samples 2 samples came as clotted, hence a total of 449 patients were included in the study. Based on haemoglobin levels the patients were divided into three groups a) severe $<7 \mathrm{~g} / \mathrm{dl}, \mathrm{b}$ ) moderate $7.0-9.9 \mathrm{~g} / \mathrm{dl}$, c) mild $10.0-11.9 \mathrm{~g} / \mathrm{dl}$. Based on WHO guidelines for anaemia in women, anaemia was defined as $\mathrm{Hb}$ level $<12 \mathrm{~g} / \mathrm{dl}$.

\section{Inclusion Criteria}

Women belonging to reproductive age group (15 -45 years).

\section{Data Collection}

A structured pre-tested interview schedule was used. Informed consent was taken prior to data collection and blood sampling from patients. A total of 446 patients were included in the study. The schedule consisted of socioeconomic and demographic information of the women such as age, religion, women education, occupation, family type, as well as other related variables such as nutrient intake, literary status according to modified B.G Prasad classification. Lifestyle behaviour variables such as consumption of fruits, green vegetables, non-vegetarian diet, pulses, milk and curd were considered.

\section{Haemoglobin Estimation}

Two ml blood sample was collected from each patient in EDTA vials and haemoglobin levels were estimated by cyanmethaemoglobin method in institute's haematology labaratory. The vial was first kept in blood mixture after which 20 microliter of blood was sucked in to the machine and the result was obtained after 1 minute.

\section{Statistical Analysis}

The data collected was entered in Microsoft excel sheet and checked for inconsistencies. The variables were assessed using chi square statistics to know the association with haemoglobin. $\mathrm{p}$ value $<0.05$ was considered significant. All analysis was carried out using SPSS 23.

\section{RESULTS}

Out of a total of 449 women who were included in the study, maximum number of patients that is $269 / 449$ (59.9\%) were found to have moderate anaemia, 93/449 (20.7\%) were found to have mild anaemia and the least number of patients i.e $76 / 449(16.9 \%)$ were found to have severe anaemia.

Maximum number of women (174) were in the age group of 25 -35 years (Table 1). 97.7\% of them were found to be anaemic (170/174). Least number of women (107) were in the age group of 35-45 years with $98 \%$ of women who were found to be anaemic (105/107). 97\% of women in age group of 15 25 years were found to be anaemic (163/168). But no statistical significance was found ( $\mathrm{p} 0.010)$.

Majority of women, i.e $93.3 \%$ belonged to Hindu religion (419/449), of whom $97.6 \%$ were found to be anaemic. $96.6 \%$ of Muslims were found to be anaemic (29/30). No statistical significance was obtained (p 0.892). 79.5\% (357/449) of women had primary education, of whom $97.7 \%$ (349/357) were found to be anaemic. $19.3 \%(87 / 449)$ received no form of education and $96.5 \%$ (84/87) of the illiterates were anaemic. $1.1 \%$ (5/449) had secondary education and all were anaemic. No statistical association was found ( $p$ 0.972). Majority of women were not working, i.e. 93.5\% (420/449). Of them, $97.3 \%$ were anaemic (409/449). 6.4\% (29/449) were in the working strata of society and all of them were anaemic. No statistical association was obtained ( $p$ 0.594). 75.9\% (341/449) of women were living in a joint family, of whom $98.2 \%(335 / 341)$ were anaemic. $24 \%(108 / 449)$ of women belonged to nuclear families, of whom 99\% (103/104) were anaemic. No statistical significance was obtained ( $p$ 0.077). Majority of women, $57.4 \%$ (258/449) belonged to lower middle class and $98 \%(253 / 258)$ were found to be anaemic. $36.9 \%(166 / 449)$ belonged to lower class and $96.3 \%$ (160/166) were anaemic. About 5.5\% (25/449) belonged to middle class according to modified B. G. Prasad classification and all were found to be anaemic. No statistical significance was obtained (Table 2)

Majority of women, i.e. $67.2 \%$ never consumed fruits and $98.6 \%$ of them were found to be anaemic. $0.8 \%$ (4/449) of women ate fruits everyday $\mathrm{n}$ all were found to be anaemic. $20.2 \%(91 / 449)$ were found to have fruits occasionally and 93.4\% (85/91) were anaemic. 11.5\% (52/449) had fruits weekly and $98 \%(51 / 52)$ were found to be anaemic. No statistical significance was obtained ( $p$ 0.333). A statistically significant association of anaemia was found ( $p$ 0.0001) with consumption of milk $\mathrm{n}$ milk products. Majority of women, 93.7\% (421/449) consumed milk n milk products weekly, of whom $99.5 \%$ were anaemic. $2.6 \%$ (12/449) consumed daily and $83.3 \%(10 / 12)$ were found to be anaemic. $0.2 \%(1 / 449)$ never consumed milk n milk products and anaemia was found in that woman. $1.7 \%(8 / 449)$ consumed occasionally and $12.5 \%(1 / 8)$ were found to anaemic. A statistically significant association was found with consumption of greens and anaemia (p 0.0001). 68.1\% (306/449) consumed greens daily and $96.4 \%$ (295/306) were found to be anaemic. $3.1 \%$ 
(14/449) were found to never consume greens and all had anaemia. 7.7\% (35/449) had greens occasionally and all were found to be anaemic. 20.9\% (94/449) consumed greens weekly and all were found to be anaemic. 96.4\% (433/449) were found to never have consumed non-vegetarian food and 97.6\% (423/433) were found to be anaemic. 3.3\% (15/449) had non-vegetarian food occasionally and all were found to have anaemia. $0.2 \%(1 / 449)$ had non-vegetarian food weekly and she was not anaemic. No woman ate non-vegetarian food every day. Statistically significant association was established, and $\mathrm{p}$ value was found to be 0.0001 . 87.9\% (395/449) consumed pulses every day and $97.2 \%$ (384/395) were found to be anaemic. $3.1 \%(14 / 449)$ consumed pulses occasionally and all were found to have anaemia. 8.9\% (40/449) consumed pulses weekly and all were found to be anaemic. No woman was found to never consume pulses. Statistically significant association was found, and p value was 0.0001 . (Table 3 , Figure 1)

\begin{tabular}{|c|c|c|c|c|c|c|}
\hline $\mathbf{H b}$ & Age 15-25 & $25-35$ & $35-45$ & Total & Chi-Square & p Value \\
\hline Severe & 35 & 28 & 13 & 76 & \multirow{4}{*}{16.240} & \multirow{4}{*}{0.010} \\
\hline Moderate & 90 & 119 & 60 & 269 & & \\
\hline Mild & 38 & 23 & 32 & 93 & & \\
\hline Normal & 5 & 4 & 2 & 11 & & \\
\hline$\%$ Anaemia & $97 \%$ & $97.7 \%$ & $98 \%$ & & & \\
\hline \multicolumn{7}{|c|}{ Table 1} \\
\hline
\end{tabular}

\begin{tabular}{|c|c|c|c|c|c|c|}
\hline \multicolumn{7}{|c|}{ Religion } \\
\hline $\mathrm{Hb}$ & & Hindu & Muslim & Total & Chi-Square & p Value \\
\hline Severe & & 70 & 6 & 76 & \multirow{4}{*}{0.621} & \multirow{4}{*}{0.892} \\
\hline Moderate & & 253 & 16 & 269 & & \\
\hline Mild & & 86 & 7 & 93 & & \\
\hline Normal & & 10 & 1 & 11 & & \\
\hline \% Anaemia & & $97.6 \%$ & $96.6 \%$ & & & \\
\hline \multicolumn{7}{|c|}{ Education Level } \\
\hline Hb & Illiterate & Primary & Secondary & Total & Chi-square & p Value \\
\hline Severe & 15 & 60 & 1 & 76 & \multirow{4}{*}{1.294} & \multirow{4}{*}{0.972} \\
\hline Moderate & 54 & 212 & 3 & 269 & & \\
\hline Mild & 15 & 77 & 1 & 93 & & \\
\hline Normal & 3 & 8 & 0 & 11 & & \\
\hline$\%$ Anaemia & $96.5 \%$ & $97.7 \%$ & $100 \%$ & & & \\
\hline \multicolumn{7}{|c|}{ Occupation } \\
\hline Hb & & Working & Non-working & Total & Chi-square & p Value \\
\hline Severe & & 70 & 6 & 76 & \multirow{4}{*}{1.898} & \multirow{4}{*}{0.594} \\
\hline Moderate & & 250 & 19 & 269 & & \\
\hline Mild & & 89 & 4 & 93 & & \\
\hline Normal & & 11 & 0 & 11 & & \\
\hline$\%$ Anaemia & & $97.3 \%$ & $100 \%$ & & & \\
\hline \multicolumn{7}{|c|}{ Family Type } \\
\hline Hb & & Joint & Nuclear & Total & Chi-square & p Value \\
\hline Severe & & 62 & 14 & 76 & \multirow{4}{*}{6.858} & \multirow{4}{*}{0.077} \\
\hline Moderate & & 197 & 72 & 269 & & \\
\hline Mild & & 76 & 17 & 93 & & \\
\hline Normal & & 6 & 5 & 11 & & \\
\hline$\%$ Anaemia & & $98.2 \%$ & $99 \%$ & & & \\
\hline \multicolumn{7}{|c|}{ Socioeconomic Class } \\
\hline Hb & Lower & Lower Middle & Middle & Total & Chi-square & p Value \\
\hline Severe & 29 & 43 & 4 & 76 & \multirow{4}{*}{3.438} & \multirow{4}{*}{0.752} \\
\hline Moderate & 93 & 159 & 17 & 269 & & \\
\hline Mild & 38 & 51 & 4 & 93 & & \\
\hline Normal & 6 & 5 & 0 & 11 & & \\
\hline$\%$ Anaemia & $96.3 \%$ & $98 \%$ & $100 \%$ & & & \\
\hline \multicolumn{7}{|c|}{ Table 2} \\
\hline
\end{tabular}

\begin{tabular}{|c|c|c|c|c|c|c|c|}
\hline $\mathrm{Hb}$ & Daily & Never & Occasionally & Weekly & Total & Chi-square & p Value \\
\hline \multicolumn{8}{|c|}{$\begin{array}{l}\text { Fruits } \\
\end{array}$} \\
\hline Severe & 1 & 49 & 18 & 8 & 76 & \multirow{4}{*}{10.218} & \multirow{4}{*}{0.333} \\
\hline Moderate & 2 & 187 & 50 & 30 & 269 & & \\
\hline Mild & 1 & 62 & 17 & 13 & 93 & & \\
\hline Normal & 0 & 4 & 6 & 1 & 11 & & \\
\hline$\%$ Anaemia & $100 \%$ & $98.6 \%$ & $93.4 \%$ & $98 \%$ & & & \\
\hline
\end{tabular}




\begin{tabular}{|c|c|c|c|c|c|c|c|}
\hline Severe & 32 & & 14 & 30 & 76 & \multirow{4}{*}{187.81} & \multirow{4}{*}{0.0001} \\
\hline Moderate & 259 & & 0 & 10 & 269 & & \\
\hline Mild & 93 & & 0 & 0 & 93 & & \\
\hline Normal & 11 & & 0 & 0 & 11 & & \\
\hline$\%$ Anaemia & $97.2 \%$ & & $100 \%$ & $100 \%$ & & & \\
\hline \multicolumn{8}{|c|}{ Curd \& Milk } \\
\hline Severe & 0 & 1 & 7 & 68 & 76 & \multirow{4}{*}{62.21} & \multirow{4}{*}{0.0001} \\
\hline Moderate & 2 & 0 & 1 & 266 & 269 & & \\
\hline Mild & 8 & 0 & 0 & 85 & 93 & & \\
\hline Normal & 2 & 0 & 0 & 2 & 11 & & \\
\hline$\%$ Anaemia & $99.5 \%$ & $100 \%$ & $12.5 \%$ & $99.5 \%$ & & & \\
\hline \multicolumn{8}{|c|}{ Non-Vegetarian Diet } \\
\hline Severe & & 73 & 3 & 0 & 76 & \multirow{4}{*}{44.122} & \multirow{4}{*}{0.0001} \\
\hline Moderate & & 263 & 6 & 0 & 269 & & \\
\hline Mild & & 87 & 6 & 0 & 93 & & \\
\hline Normal & & 10 & 0 & 1 & 11 & & \\
\hline$\%$ Anaemia & & $97.6 \%$ & $100 \%$ & $0 \%$ & & & \\
\hline \multicolumn{8}{|c|}{ Green Leafy Vegetables } \\
\hline Severe & 1 & 13 & 31 & 31 & 76 & \multirow{4}{*}{286.38} & \multirow{4}{*}{0.0001} \\
\hline Moderate & 202 & 1 & 4 & 62 & 269 & & \\
\hline Mild & 92 & 0 & 0 & 1 & 93 & & \\
\hline Normal & 11 & 0 & 0 & 0 & 11 & & \\
\hline$\%$ Anaemia & $96.4 \%$ & $100 \%$ & $100 \%$ & $100 \%$ & & & \\
\hline \multicolumn{8}{|c|}{ Table 3} \\
\hline
\end{tabular}

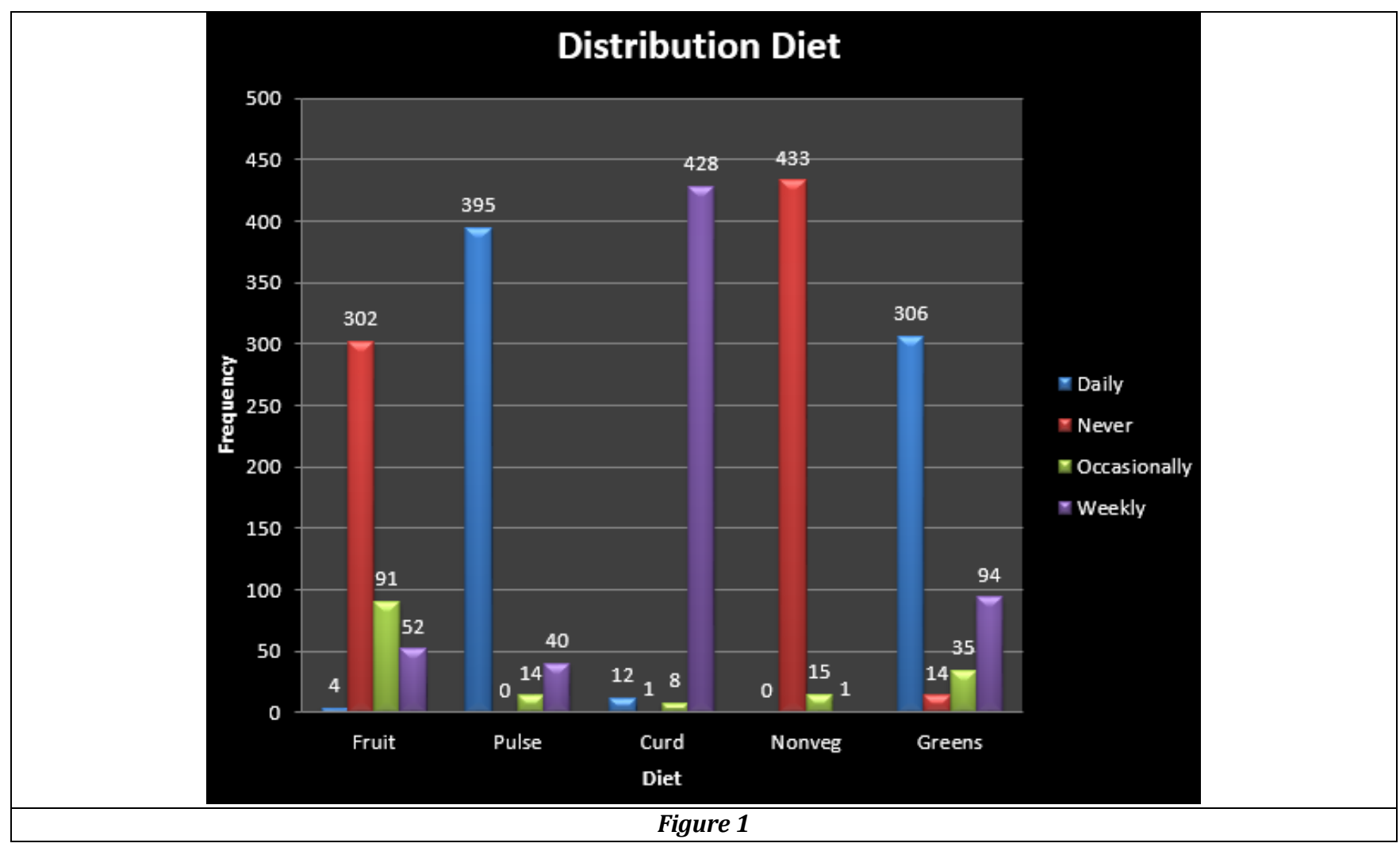

\section{DISCUSSION}

In this study, we aimed at describing the status of anaemia in women of reproductive age group and various socio demographic factors associated with it. The present study revealed a high prevalence of anaemia, i.e. $97.5 \%$ of whom $61.4 \%$ were moderately anaemic ( $\mathrm{Hb} 9.9$ to 7 ) which indicates that anaemia continues to be a major public health problem. It also is an indicator of the failure of programmes to address this problem. The magnitude of anaemia estimated in the present study was higher than that found by Satish Kumar C et al $(93 \%),{ }^{7}$ M. Shams Khan et al $(79.75 \%)^{8}$ and by S. Bisoi et al $(67.8 \%) .9$ The present study revealed predominance of moderate anaemia contrary to findings of S.Bisoi et al ${ }^{9}$ where mild anaemia was found to be more prevalent in pregnant women. This variation could be due to poverty, ignorance, non-availability of and/or failure to avail medical facilities.

Anaemia was found to be least prevalent (95\%) in age group of 35-45 years which is not significant. This is contrary to a study done by Satish Kumar et al 7 in which women more than 30 years had highest prevalence of $43.9 \%$. Our study showed that with increase in age of women, prevalence of anaemia decreased marginally as these women were more likely to have taken iron supplementations during pregnancy which might have improved their haemoglobin levels. 
Majority of women belonged to Hindu religion and $97.6 \%$ of them were anaemic. Only 6\% were Muslims and $96.6 \%$ of them were anaemic. This is similar to a study done by Satish Kumar $\mathrm{C}$ et $\mathrm{al}^{7}$ in which Hindus were in majority and $71.3 \%$ of them were anaemic. Similar finding was seen in a study done by M Shams Khan et al ${ }^{8}$ on anaemia in antenatal women where in Hindu population was in majority. A study by S. Bisoi et al ${ }^{9}$ showed prevalence of anaemia higher in Muslim population who were a minority.

In our study, no significant association of anaemia with education was seen which is similar to a study done by Vijay Kumar et al..$^{10}$ This is in contrast to study done by Satish Kumar $\mathrm{C}$ et $\mathrm{al}^{7}$ where women with higher education had lesser prevalence of anaemia. Study done by M Shams Khan et $\mathrm{al}^{8}$ on antenatal women showed lower percentage of anaemia in higher education category. Although prevalence of anaemia was more in women who were working, no significant association of anaemia with employment was seen in our study. This is in contrast to the study done by Satish Kumar C et $\mathrm{al}^{7}$ where prevalence of anaemia was higher in working women $(70.5 \%)$. In our study, prevalence of anaemia was marginally higher in nuclear family than in joint family though not statistically significant. This is in contrast to what was observed in a study by Satish Kumar C et $\mathrm{al}^{7}$ and S. Bisoi et al. ${ }^{9}$ In our study, majority of women belonged to lower middle class according to modified B. G. Prasad classification, but prevalence of anaemia was highest in middle class though statistically not significant. In a study done on pregnant women by Vijay Kumar et al, ${ }^{10}$ majority of women belonged to class 5 but prevalence of anaemia was highest in class 3 . Another study done by Satish Kumar C et al,7 majority of women belonged to the poorest category and prevalence of anaemia was the highest in the same category.

In our study, statistically significant association of anaemia with consumption of pulses, green vegetables, non-veg, milk and milk products were seen. No association of anaemia was seen with consumption of fruits. In a study conducted by Satish Kumar C et al, ${ }^{7}$ statistically significant association of anaemia was seen with consumption of fruits, pulses, green vegetables, non-vegetarian food, milk and milk products.

\section{CONCLUSION}

Incidence of anaemia was high in this area. It indicates that anaemia continues to be a major public health problem. Age, religion, literacy, occupation, family type, per capita income did not seem to affect anaemia status in women of reproductive age group, although poor dietary habits were adversely associated with anaemia in women of reproductive age group.

\section{Recommendation}

1. The study highlights the need for prevention of anaemia among women of reproductive age group through nutrition education and anaemia prophylaxis.

2. Awareness should be increased regarding need for preconception care and treatment of anaemia amongst women in reproductive age group.

3. Programmes which are aimed to provide awareness and treatment of anaemia need to be accelerated. Alternative strategies e.g. fortification of flour, oil or salt with iron; routine mass administration of albendazole; regular screening for anaemia and treatment may be considered.

\section{Limitations}

Type of anaemia not studied.

\section{REFERENCES}

[1] WHO. National Strategies for Overcoming Micronutrient Malnutrition, 1991.

[2] Editors. Movement Against Anaemia (MAA) (an Initiative of the Indian Medical Association). Indian Journal for the Practicing Doctor 2005-11 -- 200512;2:5.

[3] McLean E, Cogswell M, Egli I, et al. Worldwide prevalence of anaemia, WHO Vitamin and Mineral Nutrition Information System, 1993-2005. Public Health Nutr 2009;12(4):444-54.

[4] Ramanakumar AV. Reviewing disease burden among rural Indian women. Online J Health Allied Sci 2004;2:1.

[5] Malhotra P, Kumari S, Kumar R, et al. Prevalence of anaemia in adult rural population of north India. J Assoc Physicians India 2004;52:18-20.

[6] Sauvaget C, Ramadas K, Thomas G, et al. Body mass index, weight change and mortality risk in a prospective study in India. Int J Epidemiol 2008;37(5):990-1004.

[7] Chauhan SK, Jungari S, Chauhan BG. Burden of anaemia among women in Jharkhand, India: Does lifestyle behaviour matters? Journal of Nutrition and Health 2015;1(2):1-9.

[8] Khan SM, Srivastav A, Dixit AK. The burden of anaemia amongst antenatal women in the rural population of northern India. International Journal of Scientific Study 2014;1(4):40-42.

[9] Bisol S, Haldar D, Majumdar TK, et al. Co-relates of anaemia among pregnant women in a rural area of West Bengal. The Journal of Family Welfare 2011;57:72-8.

[10] Kumar V, Sunderam S, Haider S, et al. A study on status of anaemia in pregnant women attending urban health training centre, RIMS, Ranchi. Indian Journal of Community Health 2014;26(Suppl 2):112-7. 